\title{
A Study on Workers Reward System in Banking Sector
}

\author{
J. Prabakaran*, S. Ispriya**, A. Amsa***, T. Angulakshmi**** \\ ${ }^{1,2,3,4}$ M.Phil - Research Scholars in Commerce, Muthayammal College of Arts and Science, Rasipuram,
} Namakkal District.Tamilnadu

\begin{abstract}
This study seeks to examine the relationship between rewards and employee performance as well as to identify the relationship between extrinsic and intrinsic rewards. The study explored factors determining extrinsic and intrinsic rewards and their impact on employee performance and actions to influence the banks for a consideration of a more systematic and structured approach to acknowledge employees efforts which would in turn prosper high performance culture in banks.
\end{abstract}

Keywords: Rewards, Intrinsic rewards, Extrinsic rewards, Bank Employees performance.

\section{Introduction}

Rewards is one of the important elements to motivate employees for contributing their best effort to generate innovation ideas that lead to better business functionality and further improvise company performance both financial and non-financially. According to Dewhurst et al.(2010), there are other means to reward employees that do not just focus on financial compensation. Some of these include the praised that employees are able to acquire from their managers, the opportunity to take on important projects or tasks, and even leadership attention. Much research on leader power have found that supervisor reward power would be positively associated with employee task performance, productivity, satisfaction, turnover, and organizational citizenship behaviors( Simon,1976; Martin \& Hunt, 1980; Jahangir,2006).

Employee will give their maximum when they have a feeling or trust that their efforts will be rewarded by the management. There are many factors that affect employee performance like working conditions, worker and employer relationship, training and development opportunities, job security, and company's overall policies and procedures for rewarding employees, etc. Among all those factors which affect employee performance, motivation that comes with rewards is of utmost importance. Motivation is an accumulation of different processes which influence and direct our behavior to achieve some specific goal (Baron, 1983).Rewards can be extrinsic or intrinsic, extrinsic rewards are tangible rewards and these rewards are external to the job or task performed by the employee. External rewards can be in terms of salary/ pay, incentives, bonuses, promotions, job security, etc. Intrinsic rewards are intangible rewards or psychological rewards like appreciation, meeting the new challenges, positive and caring attitude from employer, and job rotation after attaining the goal.

According to Luthans (2000), there are two basic types of rewards, financial and non-financial and both can be utilized positively to enhance performance behaviors of employees. Financial rewards means pay-for performance such as performance bonus, job promotion, commission, tips, gratuities and gifts etc. Non financial rewards are non monetary/non cash and it is a social recognition such as acknowledgement, certificate, and genuine appreciation etc. The non financial rewards is also called materials award (Neckermann and Kosfeld,2008).

\section{Reward Systems}

This study involves intrinsic and extrinsic rewards as independent variables. In independent variable extrinsic reward includes three dimensions such as basic pay, merit pay and performance bonus. As for the intrinsic reward, it includes four dimensions such as recognition, learning opportunity, challenging work and career advancement.

\section{Bank Employees' Performance}

This study involves employees' performance as dependent variable. In dependent variable employee performance encompasses three dimensions such as productivity, job quality and job accomplishment.

\section{Reward Basics}

Employees often receive rewards in addition to their base salary depending on their achieved results, performance, competence, or skill acquisition2. Rewards have many aims as illustrated in Table 1. Among others they shall reduce time, and cost and improve quality (Tinnirello 2001); they shall reward people for the value they created (Armstrong \& Murlis 2004) and they shall help communicate the company"s values and expectations (Armstrong 2002). Since rewards mean additional costs to the organisation, the overall aim is 
providing "value for money" and contributing to organizational success (Armstrong 2002:14). In the case of project management, it was concluded, rewards shall provide value for money to the project and contribute to project success. Rewards cannot directly affect success. The direct affect of rewards is on employees "motivation. Various definitions of motivation exist. For this thesis, employees" motivation is seen as the employees" desire to work and perform well in order to contribute to organizational or project success3. Two types of motivation exist: Intrinsic and extrinsic motivation. Intrinsic motivation is "self-generated" and means employees are motivated to work because of the work (Armstrong 2002:56). Extrinsic motivation is generated by external stimulus such as rewards (Armstrong 2002).

\section{Rewards $\rightarrow$ Motivation $\rightarrow$ Performance $\rightarrow$ Success}

\section{Objectives Of A Reward Scheme}

1. The effect of intrinsic rewards on employee's performance.

2. The effect of extrinsic rewards on employee's performance.

3. The relationship between extrinsic and intrinsic rewards.

4. To support the goals of the organization by aligning the goals of employees with these.

5. To motivate employees.

6. To be ethical.

7. To be affordable and easy to administer.

\section{Internal And External Reward Factors}

The modest reward proponents' argument is that some variable factors influence the decision which reward answer is suitable in a certain situation. For this thesis, the identified factors were classified as internal reward factors and external reward factors (see Table 4 for a list). Internal reward factors are in the direct sphere of influence of the organization or its employees.

External reward factors are not in the direct sphere of influence of the organization or its employees. From the literature review, the internal reward factors could further be divided into five categories (see Table 4). The external reward factors were divided into two categories (see Table 4). Each of the categories contains a number of factors influencing the right choice of the reward answers. For instance, the employees' "age is an internal individual reward factor. The age influences the reward target: Older people are less likely to like team rewards and hence should be rewarded individually (Demotte 1997). Further influences of the internal and external reward factors are covered in the next sections.

\section{Motivation Theories}

During the 20th century, different motivation theories originated focusing on individual "s motivation. The theories were mostly developed by psychologists and are of a general nature. They are usually not specifically designed for the "world of work" or even rewarding employees (Furnham 1997:248). Academics and managers just apply the theories to employees" motivation and development of reward systems. This may lead to

Different interpretations and different opinions on how rewards influence employees motivation.

\section{Reward Decision}

Available tools for assessing employees may influence the reward decision in combination with the task characteristics (Torrington et al. 2002). For instance, simple tasks are easier to assess (Torrington et al. 2002). Sometimes the assessment even can be done by automatic surveillance systems. In contrast, complex and difficult tasks need highly skilled assessors who know how to apply and perform tools such as $360^{\circ}$ feedbacks (McKeon 2002). Hence, the more certain a "good" assessment is, the more likely rewards should be used (Armstrong \& Murlis 2004).

\section{Reward Target}

Four main objectives exist that can be rewarded (Armstrong 2002). These are employees" results, performance, competence, and skills. The discussion about the reward target focuses on the influence of the task characteristics.

\section{Reward Type}

The term reward functions as an "umbrella" (Filipczak 1993:20) for incentives and recognition. Figure 4 (next page) provides a comparison between recognition and incentives and Table 8 (next page) some 
examples. Incentives tend to be financial rewards given for reaching an agreed objective. Their purpose is to motivate employees

Recognition tends to be a non-financial reward or financial reward with a rather symbolic character. It is given to employees spontaneously and the purpose is to appreciate the work that employees" did in the past. The exact distinction is often difficult (Filipczak 1993). Incentives become recognition in the moment they are given. Recognition may become motivational if employees expect to get the recognition.

\section{Reward Extent}

Reward proponents agree that if an incentive should act as motivator it has to be significant (e.g. Armstrong 2000, Tinnirello 2001, and Harvard 2000). This can be explained by the expectancy theory, which states that an incentive has to be valuable enough to justify the effort (see Table 5, p. 15). In practice, rewards often are 2 or $3 \%$ of the base salary (Torrington et al. 2002).

\section{Reward Time}

Gibson \& Cohen (2003:123) emphasise that rewards should be given in a "timely fashion". Orr (2004) clarifies this statement by saying rewards should be given directly after a goal was reached. In normal line work, goals are agreed and assessed usually once a year. Accordingly, incentives are given once a year (Torrington et al. 2002). In contrast, recognition might be given more frequently to employees (Garg \& Rastogi 2006). This reminds employees of the overall goal (and incentive) and brings positive change into employees daily routine.

\section{Summary And Evaluation}

The modest reward proponents engage deeply with the six reward questions and propose that all reward answers may be valid answers, depending on the variable reward factors. Their perspective is supported by empirical research and most motivation theories. They do not and cannot provide definite instructions how to answer the reward questions in a certain situation.

\section{Conclusion}

A good reward system aims to motivate employees to work harder, and align their goals with those of the organization they work for. The current trend towards performance-related reward systems is designed to lead to greater rewards and motivation for those who contribute the most. However, designing such reward systems is complex, as they aim to influence human behavior. As the human resources director of Flow pack Engineering said (quoted in Bratton) 'There is no such thing as a good pay system; there is only a series of bad ones. The trick is to choose the least bad one.'

\section{References}

[1]. Bratton and Gold, Human Resource Management Theory and Practice, 4th edition chapter 10, Palgrave Macmillan, 2007

[2]. Hope and Fraser, Beyond Budgeting, Harvard Business School Press, 2003

[3]. Val, M \& Fuentes, CM 2003, „Resistance to change: a literature review and empirical study “, Management Decision, vol. 41, no. 2, pp. $148-155$.

[4]. Velde, M Jansen, P \& Anderson, N 2004, Guide To Management Research Methods, Blackwell Publishing, Carlton.

[5]. Volkswagen, Volkswagen Coaching GmbH 2003, Stand und Trend des Project managements in Deutschland, Books on Demand Websites $\mathrm{GmbH}$, Norderstedt.

[1]. www.wikipedia.com

[2]. www.rewardsystem.com 